\title{
Billing fees for various common allergy tests vary widely across Canada
}

\author{
Jennifer Lisa Penner Protudjer $r^{1,2,3,4,5,6^{*}}$ (0), Lianne Soller ${ }^{7,8}$, Elissa Michelle Abrams ${ }^{1,7}$ and Edmond S. Chan 7,8
}

\begin{abstract}
Background: The prevalence of food allergy in Canada is high and has increased over time. To date, there are no Canadian data on the healthcare costs of visits to allergists.

Methods: We sent an anonymous survey to allergist members of the Canadian Society of Allergy and Clinical Immunology (CSACI) between October and December 2019. Survey questions included demographic information and billing fees for various types of allergy visits and diagnostic testing.

Results: Of 200 allergists who are members of CSACl, 43 allergists responded (21.5\% response rate). Billing fees varied widely. The greatest ranges were noted for oral immunotherapy (OIT; both initial consultation [mean \$198.70; range $\$ 0$ to $\$ 575$ ] and follow up/build up visits [mean \$125.74; range: \$0 to \$575]). There were significant provincial differences in billing fees, as well as significant billing fee differences between hospital versus community allergists (e.g. oral food challenge [OFC]: \$256.38 vs. \$134.94, p<0.01). Billing fees were higher outside of Ontario, with the exception of specific Immunoglubulin E (slgE) testing and OIT visits.
\end{abstract}

Conclusions: Greater standardization of billing fees across provinces and between hospital versus community allergy could result in more consistency of billing fees for OFC and OIT across Canada. Further knowledge of exact costs will help inform practice and policy in the diagnosis and management of food allergy.

Keywords: Billing costs, Food allergy, Health Economics, Oral immunotherapy

\section{Background}

The prevalence of food allergy is at an all-time high [1], and impacts household costs [2], by age but not disease severity [3]. In one study, families of children and adolescents with food allergy reported excess annual household costs of approximately $\$ 6200$ Canadian (CAD) and $\$ 7500 \mathrm{CAD}$, respectively, compared to families without food allergy. Families living with food allergy also report poor quality of life [4-9] and food allergy-related bullying [10]. Healthcare related costs have also been described [11]. Data from the United States indicate that the annual cost of food allergy to the healthcare system

\footnotetext{
*Correspondence: Jennifer.Protudjer@umanitoba.ca

${ }^{6}$ Food and Human Nutritional Sciences, The University of Manitoba, Winnipeg, Canada

Full list of author information is available at the end of the article
}

is approximately $\$ 4.3$ billion [11]. With an estimated selfreported prevalence of $7-8 \%$, the rates of food allergy are comparable between the United States [12] and Canada $[13,14]$. Owing to differences in healthcare systems, cost comparisons between Canada and elsewhere are challenging for many reasons. For example, unlike in the United States, access to healthcare and medication in Canada is generally not dependent on private insurance. Thus, the American cost estimates reported by Gupta et al. [11] are unlikely to reflect Canadian healthcare costs.

At present, there are no published Canadian data on the cost of food allergy to the healthcare system, particularly the cost of healthcare visits to allergists. Moreover, the Canadian Institute for Health Information (CIHI) does not report on billing fees for allergists who treat patients with food allergy. Rather, there are only

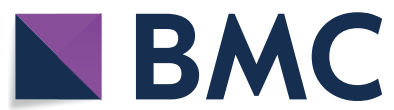

(c) The Author(s) 2020. This article is licensed under a Creative Commons Attribution 4.0 International License, which permits use, sharing, adaptation, distribution and reproduction in any medium or format, as long as you give appropriate credit to the original author(s) and the source, provide a link to the Creative Commons licence, and indicate if changes were made. The images or other third party material in this article are included in the article's Creative Commons licence, unless indicated otherwise in a credit line to the material. If material is not included in the article's Creative Commons licence and your intended use is not permitted by statutory regulation or exceeds the permitted use, you will need to obtain permission directly from the copyright holder. To view a copy of this licence, visit http://creativeco mmons.org/licenses/by/4.0/. The Creative Commons Public Domain Dedication waiver (http://creativecommons.org/publicdomain/ zero/1.0/) applies to the data made available in this article, unless otherwise stated in a credit line to the data. 
published data on the number of emergency department visits for anaphylaxis and allergy [15]. But, the majority of patients with food allergy do not routinely-or everseek emergency care [16, 17]. As such, the ability to estimate non-emergency-related healthcare costs for food allergy is a necessary first step in establishing the costs of food allergy to the Canadian healthcare system. To this end, we aimed to provide a benchmark for government-paid reimbursement for common allergy tests amongst physicians, and for provinces looking at adjusting service fees.

\section{Methods}

This anonymous survey was open between October and December 2019 to allergists who see children and/or adults for food allergy-related concerns. Allergists were recruited through the Canadian Society of Allergy and Clinical Immunology (CSACI) database, which includes the majority of Canadian allergists (approximately 200).

Potential participants received an introductory email, which contained a brief summary of the study and study team. If participants agreed to continue to the questionnaire, consent was assumed. We did not collect names or contact details of participants.

The questionnaire included demographic questions (province, hospital or community practice) and billing fees for various food allergy-related visits: initial diagnosis of food allergy, follow up visit for food allergy, oral food challenge (OFC), initial visit for oral immunotherapy (OIT), OIT build up visit, skin prick test, and ImmunoCap test (specific Immunoglobulin [sIgE] blood test). The questionnaire was created in Survey Monkey®, with results aggregated and sent to the first author.

Location of practice was self-reported as either community or hospital. Provincial level data were provided for each type of food allergy-related visit. No allergists are known to have a primary practice in any of the three Canadian territories (Yukon, Northwest Territories, Nunavut).

\section{Statistical analysis}

If an allergist provided a cost range for any of the queried services (initial diagnosis; follow up visit; OFC; initial visit for OIT; OIT build up visit, SPT; sIgE, the mean of the range was used. If the allergist parceled out costs based on billing party (i.e. allergist vs. hospital), these amounts were summed to ascertain the full billing amount. If an allergist reported that the costs were covered by his/her respective provincial health authority, and/or noted that these costs were comparable to other forms of consults, and/or gave a cost per hour, and/or selected "don't know" and/or did not provide any quantitative data, their results were excluded from the analysis.

Data were analysed using descriptive statistics $(\mathrm{n} / \mathrm{N}, \%$, mean, standard deviation, range, t-tests, Mann-Whitney U-tests). A $p$ value $<0.05$ was considered statistically significant. Data were analysed using Stata 15.1 (College Station, TX). Analyses were performed on the entire data set. Subsequently, billing fees were compared between community vs. hospital allergists. Then, comparisons of billing fees were made between provinces, with the most commonly reported province (Ontario), as the reference location. Finally, we made comparisons between community vs. hospital allergists in provinces where sample sizes were sufficient for robust analyses. This study was approved by The University of Manitoba Health Research Ethics Board HS23227 (H2019:367).

\section{Results}

Of approximately 200 allergist members of CSACI, 43 allergists participated in this survey (response rate $=21.5 \%)$. Most responding allergists $(30 / 43 ; 69.8 \%)$ reported a community practice location (Table 1 ). Nearly half of allergists reported practicing in Ontario (19/43; $44.2 \%)$. Fewer allergists reported a location of practice in Quebec $(10 / 43 ; 23.3 \%)$ or provinces in Western Canada (British Columbia 5/43; 11.6\%; Alberta 4/43; 9.3\%; Saskatchewan 0/43; 0\%; Manitoba $2 / 32 ; 4.7 \%$ ). Few allergists from Atlantic Canada participated (Nova Scotia 2/43; 4.7\%; Newfoundland and Labrador 1/42; 2.3\%).

For all common allergy tests, billing fees varied widely. The mean billing fee for an initial visit for food allergy was $\$ 205.60$, but ranged from $\$ 122$ to $\$ 500$ (Table 2). Of

\begin{tabular}{|c|c|c|}
\hline & $\mathbf{N}$ & $\%$ \\
\hline \multicolumn{3}{|l|}{ Practice location } \\
\hline Community & 30 & 69.8 \\
\hline Hospital & 13 & 30.2 \\
\hline \multicolumn{3}{|l|}{ Geographic location of practice } \\
\hline British Columbia & 5 & 11.6 \\
\hline Alberta & 4 & 9.3 \\
\hline Saskatchewan & 0 & 0.0 \\
\hline Manitoba & 2 & 4.7 \\
\hline Ontario & 19 & 44.2 \\
\hline Quebec & 10 & 23.3 \\
\hline Nova Scotia & 2 & 4.7 \\
\hline Prince Edward Island & 0 & 0.0 \\
\hline New Brunswick & 0 & 0.0 \\
\hline Newfoundland and Labrador & 1 & 2.3 \\
\hline
\end{tabular}


Table 2 Mean billing fees (CAD) for common allergy visits and tests $(\mathrm{N}=43)$

\begin{tabular}{lrrrl}
\hline & \multicolumn{4}{l}{ All responding allergists } \\
\cline { 2 - 5 } & N & Mean & $\begin{array}{c}\text { Standard } \\
\text { deviation }\end{array}$ & Range \\
\hline Initial visit & 42 & 205.60 & 73.29 & $122-500$ \\
Follow up visit & 42 & 88.66 & 45.60 & $40-300$ \\
Oral immunotherapy & & & & \\
Initial visit & 34 & 198.79 & 153.15 & $0-625$ \\
Build up/follow up & 33 & 125.74 & 146.08 & $0-575$ \\
Oral food challenge & 36 & 172.05 & 132.61 & $4.60-600$ \\
Skin prick testing & 42 & 11.82 & 23.88 & $0.08-110$ \\
Blood testing (slgE) & 35 & 13.40 & 14.10 & $0-40$ \\
\hline
\end{tabular}

the allergists reporting initial visit fees greater than the mean, 76.9\% (10/13) practiced in Western Canada.

The greatest ranges for all billing fees were noted for OIT, where an initial visit was charged at a mean of $\$ 198.70$, but ranged from $\$ 0$ to $\$ 625$ (Fig. 1c). Of the allergists reporting initial OIT visit fees greater than the mean, 34.8\% (8/23) practiced in Ontario and 21.7\% (5/23) practiced in Quebec.

For a build up/follow up OIT visit, the mean billing fee was $\$ 125.74$, but ranged from $\$ 0$ to $\$ 575$ (Fig. 1d). Of the allergists reporting build up/follow up OIT visit fees greater than the mean, $47.6 \%(10 / 21)$ practiced in Ontario and 38.1\% (8/21) practiced in Quebec.

The narrowest range of billing fees was reported for sIgE testing, with a mean of $\$ 13.40$, and a range of $\$ 0-\$ 40$ (Fig. 1g). Excluding all reported billing fees of $\$ 0$ did not dramatically alter the mean of the various billing fees. With these exclusions, the corresponding numbers were, OIT initial visit: mean $\$ 241$, range $\$ 59$ to $\$ 625$; OIT build up/follow up: mean $\$ 159$, range $\$ 10$ to $\$ 575$; blood (sIgE) testing: mean $\$ 25$, range $\$ 10$ to $\$ 40$.

Compared to community allergists, hospital allergists had higher billing fees for OFC (\$134.94 vs. \$256.38, $\mathrm{p}<0.01$ ), but not other common allergy tests such as initial or follow up visits, visits related to OIT, or SPT or sIgE testing.

Compared to Ontario, mean billing fees in other parts of Canada were significantly higher for initial and follow up visits for food allergy ( $\$ 174.65$ vs. $\$ 228.82, \mathrm{p}<0.01$; $\$ 71.00$ vs. $\$ 101.90, \mathrm{p}<0.001$, respectively), OFC ( $\$ 93.21$ vs. $\$ 222.22, \mathrm{p}=0.03)$, skin prick tests $(\$ 1.05$ vs. $\$ 19.90$, $\mathrm{p}<0.01$ ); but not for OIT initial visits or build up/follow up visits, or blood sIgE testing (all $\mathrm{p}>0.05$ ).

Comparisons of billing fees between community and hospital-based allergists within a province were possible in Ontario $(n=16, n=3$, respectively) and Quebec $(n=3$; $\mathrm{n}=7$, respectively), but not other provinces due to small sample size. In these two provinces, billing fees did not differ (all $\mathrm{p}>0.05$ ) by location of practice. Of note, no Quebec-based community allergists reported billing fees for follow up visits for OIT.

\section{Discussion}

In this survey of Canadian allergists, the reported billing fees for various common allergy tests varied widely, with widest ranges noted for initial OIT visits and build up/ follow up OIT visits. At a national level, billing fees were comparable between community vs. hospital allergists with the exception of billing fees for OFC, which were significantly higher amongst hospital allergists. At a provincial level, differences were attenuated, which could be due to small sample sizes. Billing fees were higher in other parts of Canada compared to Ontario, with the exception of OIT initial/follow-up visits and sIgE testing.

Interestingly, fewer allergists responded to questions on OIT billing fees than other common allergy tests. Although it would be incorrect to assume based on this finding alone that not all allergists who provide consultation for food allergy offer OIT, roughly 34 allergists providing initial OIT visits out of 42 allergists providing initial food allergy visits $(81 \%)$ is higher than that of an American report in which only about $14 \%$ of allergists reported using OIT [18]. We also acknowledge that Canadian provinces have not yet introduced billing fee codes for OIT, which may explain why some allergists reported a fee of $\$ 0$ for this procedure (i.e. $\$ 0$ may have represented the government billing fee amount while not capturing the privately billed amount.)

Overall, hospital allergists reported higher billing fees for OFC than community allergists, although these differences are not significant in Ontario and Quebec, the provinces for which sample size permitted comparison, but which may nonetheless be too small to detect any differences. OFCs are the gold standard to establish a diagnosis of food allergy or the development of tolerance. Importantly, it is possible that community allergists may refer to hospital-based allergists for higher risk challenges, whereas those completed in the community may be performed to confirm tolerance. This practice aligns with recommendations from the United States, in which sIgE and SPT have been shown to be useful in determining the most appropriate place to perform an OFC [19]. At the same time, we recently reported that many allergists view a lack of resources, inconsistent standards between hospital and community practices [20], and a lack of comfort [21] as barriers to performing OFCs. These barriers warrant consideration going forward, as does a comprehensive cost-effectiveness analysis of OIT. 
a Initial visit

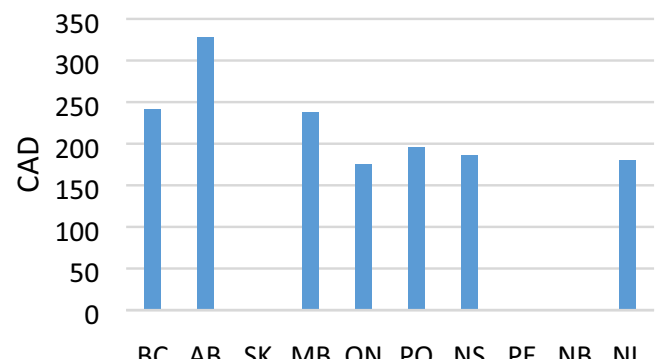

c OIT Initial Visit

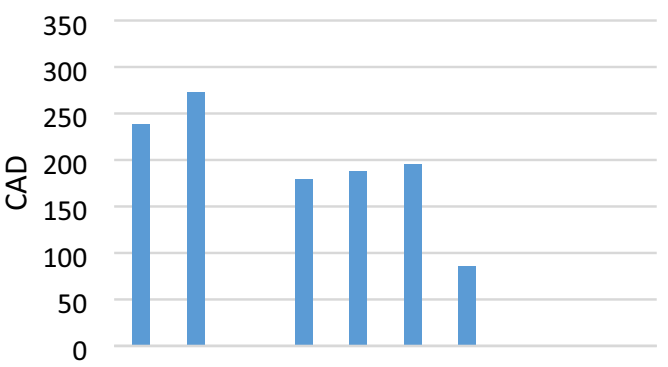

BC AB SK MB ON PQ NS PE NB NL

e OFC

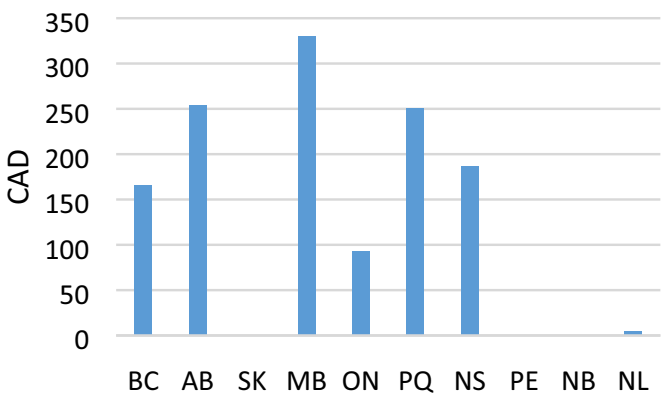

g Blood IgE

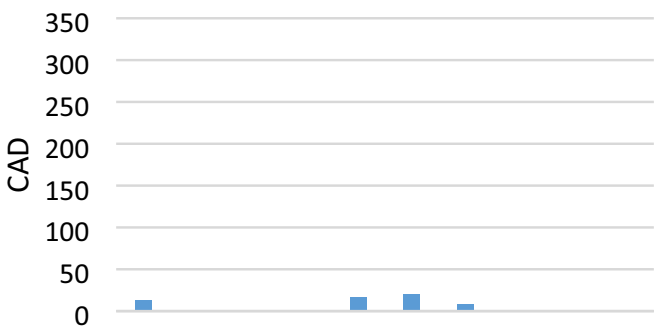

$B C$ AB SK MB ON PQ NS PE NB NL b Follow Up

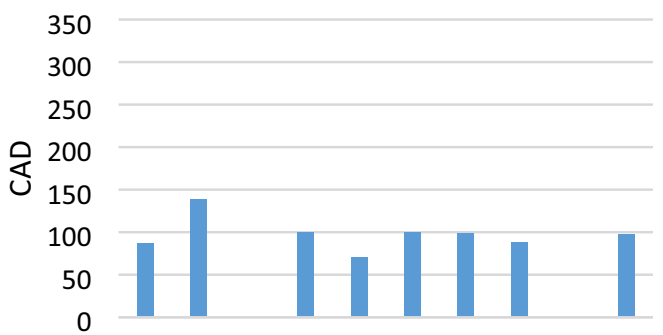

$B C \quad A B$ SK MB ON PQ NS PE NB NL

\section{d OIT Follow Up}

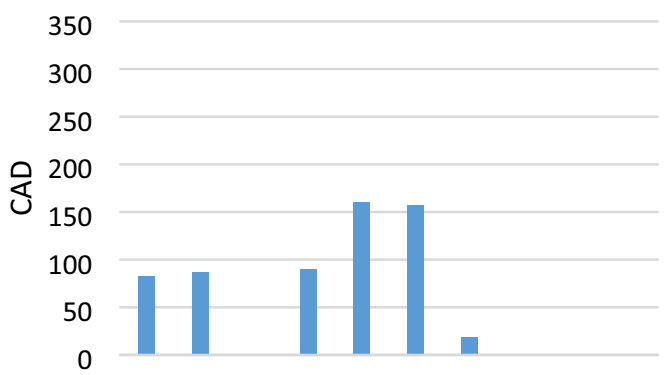

$B C \quad A B \quad S K \quad M B$ ON PQ NS PE NB NL

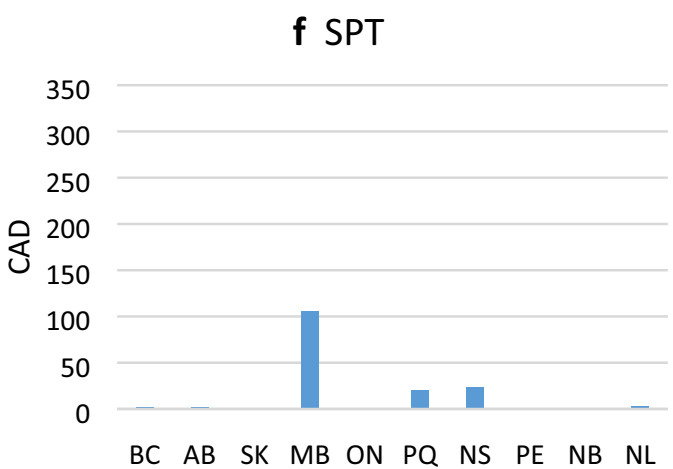

Fig. 1 Billing fees (CAD) for common allergy visits and tests, by province 
Billing fees in Ontario were significantly lower for initial and follow up visits for food allergy than in other Canadian provinces. This may be partly explained by a tendency for more private billing in Ontario than other parts of Canada.

We acknowledge the limitations of our study, including a response rate of $21.5 \%$. However, this rate parallels the response rate in a 2018 survey of CSACI members of $22 \%$ [21], and highlights an overall decreasing temporal trend in response rates in recent years [20-22]. As a result of this low response rate, sample sizes were low. For provinces other than Ontario and Quebec, we were not able to compare billing fees at a provincial level. Lastly, our study did not distinguish between billing fees paid to allergists by their provincial government versus fees paid out-of-pocket by patients. Likewise, we did not identify the province(s) in which fees were paid out-ofpocket although it is common knowledge that Ontario labs outside of hospitals charge patients privately for sIgE testing and some Ontario allergists charge privately for OIT [23].

We highlight that this is the first Canadian study to estimate billing fees for common allergy visits and tests. These estimates are essential to better understand the health economic impact of food allergy, and should be used in combination with healthcare register data to calculate non-emergent allergy-related costs. Moreover, these estimates will form part of further economic analyses by our group of the cost burden of OIT, and may inform other cost analyses, including comparisons between common allergy tests. The prevalence of food allergy is at an all-time high, and disproportionately affects children, including many who are unlikely to outgrow their allergies [1]. Thus, accurate estimates of the cost burden beyond emergency department visits for allergy and anaphylaxis are critical for healthcare planning and policy in Canada.

\section{Conclusions}

Billing fees for various common allergy visits and tests vary widely across Canada, with the widest ranges reported for OIT. Overall, hospital allergists report higher billing fees for OFC than community allergists. Such differences were attenuated in provincial level comparisons. Billing fees are higher outside of Ontario, with the exception of OIT visits and sIgE testing. These data provide a benchmark for reimbursement for OIT amongst physicians, as well as for provinces looking to adjust billing fees. Greater standardization of billing fees across provinces and between hospital versus community allergy could result in more consistency of billing fees for OFC and OIT across Canada. Further knowledge of exact costs will help inform practice and policy in the management of food allergy.

\begin{abstract}
Abbreviations
CAD: Canadian Dollars; CIHI: Canadian Institute for Health Information; CSACI: Canadian Society of Allergy and Clinical Immunology; slgE: Specific Immunoglobulin E; OFC: Oral Food Challenge; OIT: Oral immunotherapy.
\end{abstract}

\section{Acknowledgements}

Open access funding provided by Karolinska Institute.

\begin{abstract}
Authors' contributions
JP co-designed and performed the analysis, and drafted the manuscript. LS co-designed the study, and provided critical input in the interpretation of the results and preparation of the manuscript. EMA provided critical input in the interpretation of the results and preparation of the manuscript. ESC provided critical input in the interpretation of the results and preparation of the manuscript. All authors read and approved the final manuscript.
\end{abstract}

\section{Funding}

Funding for this project was provided by J Protudjer's Start Up funds from The University of Manitoba, and The Children's Hospital Research Institute of Manitoba. These funding bodies had no influence on the study design; data collection, analysis and interpretation; or, manuscript writing.

\section{Availability of data and materials}

The datasets analysed in the current study are not publicly available due to the real potential of identifying individual allergists in regions with few practicing allergists.

EMA is a member of the healthcare advisory board for Food Allergy Canada. ESC has received research support from DBV Technologies, has been a member of advisory boards for Pfizer, Pediapharm, Leo Pharma, and Kaleo, is a member of the healthcare advisory board for Food Allergy Canada, was an expert panel and coordinating committee member of the National Institute of Allergy and Infectious Diseases (NIAID)-sponsored Guidelines for Peanut Allergy Prevention, and is co-lead of the CSACl oral immunotherapy guidelines.

\section{Ethics approval and consent to participate}

Ethical permission was granted by the University of Manitoba Health Research Ethics Board HS23227 (H2019:367). Consent was assumed if participants completed the anonymous survey.

\section{Consent for publication}

Not applicable.

\section{Competing interests}

JP declares no real or perceived conflict of interest in relation to this manuscript. LS has received research support from DBV Technologies.

\section{Author details}

${ }^{1}$ Department of Pediatrics and Child Health, The University of Manitoba, 501G-715 McDermot Avenue, Winnipeg, MB R3E 3P4, Canada. ${ }^{2}$ George and Fay Yee Centre for Healthcare Innovation, Winnipeg, Canada. ${ }^{3}$ The Children's Health Research Institute of Manitoba, Winnipeg, Canada. ${ }^{4}$ Institute of Environmental Medicine, Karolinska Institutet, Stockholm, Sweden.

${ }^{5}$ Centre for Allergy Research, Karolinska Institutet, Stockholm, Sweden. ${ }^{6}$ Food and Human Nutritional Sciences, The University of Manitoba, Winnipeg, Canada. ${ }^{7}$ Division of Allergy \& Immunology, Department of Pediatrics, Faculty of Medicine, The University of British Columbia, Vancouver, BC, Canada. ${ }^{8}$ BC Children's Hospital Research Institute, Vancouver, BC, Canada.

Received: 5 February 2020 Accepted: 13 April 2020

Published online: 22 April 2020 


\section{References}

1. Sicherer SH, Sampson HA. Food allergy: a review and update on epidemiology, pathogenesis, diagnosis, prevention, and management. J Allergy Clin Immunol. 2018;141(1):41-58

2. Protudjer $\mathrm{J}$, Jansson $S A$, Heibert Arnlind $M$, Bengtsson U, KallströmBengtsson I, Marklund B, et al. Household costs associated with objectively diagnosed allergy to staple foods in children and adolescents. J Allergy Clin Immunol. 2015;3(1):68-75.

3. Wai HM, Middelveld R, Thornqvist V, Ballardini N, Nilsson E, Stromquist $J$, et al. Pediatric food allergy-related household costs are influenced by age, but not disease severity. World Allergy Org J. 2019;12(9):100061.

4. Protudjer JLP, Jansson SA, Middelveld RJM, Östblom E, Dahlén S-E, Heibert Arnlind $M$, et al. Impaired health-related quality of life in adolescents with allergy to staple foods. Clin Trans Allergy. 2016;6:37.

5. Protudjer JLP, Jansson SA, Östblom E, Heibert Arnlind M, Bengtsson U, Dahlen S-E, et al. Health-related quality of life in children with objectivelydiagnosed staple food allergy assessed with a disease-specific questionnaire. Acta Paediatr. 2015;104(10):1047-54.

6. Thörnqvist V, Middelveld R, Wai HM, Ballardini N, Nilsson E, Strömquist $J$, et al. Health-related quality of life worsens by school age amongst children with food allergy. Clin Trans Allergy. 2019;9:10.

7. Birdi G, Cooke R, Knibb RC. Quality of life, stress and mental health in parents of children with parentally diagnosed food allergy compared to medically diagnosed and healthy controls. J Allergy. 2016:2016:1497375.

8. Flokstra-de Blok BM, Dubois AE, Vlieg-Boerstra BJ, Oude Elberink JN, Raat H, DunnGalvin A, et al. Health-related quality of life of food allergic patients: comparison with the general population and other diseases. Allergy. 2010;65(2):238-44.

9. Greenhawt M. Food allergy quality of life and living with food allergy. Curr Opin Allergy Clin Immunol. 2016;16(3):284-90.

10. Fong $A T$, Katelaris $\mathrm{CH}$, Wainstein BK. Bullying in Australian children and adolescents with food allergies. Pediatr Allergy Immunol. 2018:29(7):740-6.

11. Gupta R, Holdford D, Bilaver L, Dyer A, Holl JL, Meltzer D. The economic impact of childhood food allergy in the United States. JAMA Pediatr. 2013;167(11):1026-31

12. Gupta RS, Springston EE, Warrier MR, Smoth B, Kumar R, Pongracic J, et al. The prevalence, severity, and distribution of childhood food allergy in the United States. Pediatrics. 2011;128(1):e9-17.
13. Soller L, Ben-Shoshan M, Harrington DW, Fragapane J, Joseph L, St Pierre $Y$, et al. Overall prevalence of self-reported food allergy in Canada. J Allergy Clin Immunol. 2012;130(4):986-8.

14. Clarke AE, Elliott SJ, St Pierre Y, Soller L, La Vieille S, Ben-Shoshan M. Temporal trends in prevalence of food allergy in Canada. J Allergy Clin Immuonol Pract. 2019;8(4):1428-30.

15. Information $\mathrm{CIfH}$. Anaphylaxis and allergy in the emergency department. 2015.

16. Keijzers G, Sweeny A, Crilly J, Good N, Camerson CM, Mihala G, et al. Parental-reported allergic disorders and emergency department presentations for allergy in the first five years of life; a longitudinal birth cohort. BMC Pediatr. 2018;18:1.

17. Vetander M, Protudjer J, Lilja G, Kull I, Hedlin G, van Hage M, et al. Anaphylaxis to foods in a population of adolescents: incidence, characteristics and associated risks. Clin Exp Allergy. 2016;46(12):1575-87.

18. Greenhawt MJ, Vickery BP. Allergist-reported trends in the practice of food allergen oral immunotherapy. J Allergy Clin Immunol. 2015;3(1):33-8.

19. SimberloffT, Parambi R, Bartnikas LM, Broyles AD, Hamel V, Timmons KG, et al. Implementation of a Standardized Clinical Assessment and Management Plan (SCAMP) for Food Challenges. J Allergy Clin Immunol. 2017:5(2):335-44

20. Hsu E, Soller L, Abrams EM, Protudjer JL, Mill C, Chan ES. Oral food challenge implementation: the first mixed-methods study exploring barriers and solutions. J Allergy Clin Immunol. 2019;8(1):149-56.

21. Abrams EM, Soller L, Singer AG, Fleischer DM, Greenhawt M, Chan ES. Comparison of practice patterns among Canadian allergists before and after NIAID guideline recommendations. J Allergy Clin Immunol. 2019;7(8):2901-3

22. Abrams EM, Singer AG, Soller L, Chan ES. Knowledge gaps and barriers to early peanut introduction among allergists, pediatricians, and family physicians. J Allergy Clin Immunol. 2019;7:681-4.

23. Allergy, Asthma \& Immunology Society of Ontario. Allergy in today's word-what does the allergist do? 2020. http://allergyasthma.on.ca/ what-is-an-allergist/.

\section{Publisher's Note}

Springer Nature remains neutral with regard to jurisdictional claims in published maps and institutional affiliations.
Ready to submit your research? Choose BMC and benefit from:

- fast, convenient online submission

- thorough peer review by experienced researchers in your field

- rapid publication on acceptance

- support for research data, including large and complex data types

- gold Open Access which fosters wider collaboration and increased citations

- maximum visibility for your research: over 100M website views per year

At $B M C$, research is always in progress.

Learn more biomedcentral.com/submissions 